8. Demchyshhyn O. V., Kuhtyn M. D., Perkij Ju. B., Stravs'kyj Ja. S. Efficiency of the application of the "Acquasan" acidified activated charcoal chicken broilers. Veterinary medicine, 2018, vol. 104, pp. 250-253. (in Ukrainian).

9. Demchyshhyn O. V., Kuhtyn M. D., Perkij Ju. B., Gorjuk Ju. V. Effect of Acid Oxidant on the Microbiocenosis of Intestines of Chicken Broilers. Veterinary biotechnology. Bulletin, 2018, vol. 33, pp. 25-30. (in Ukrainian). https://doi.org/10.31073/vet_biotech33-03

10. Demchyshhyn O. V., Kuhtyn M. D., Perkij Ju. B. Assessment of the quality of chickenbroiler meat for the delivery of "Acquasan" Acidifier. Scientific herald of the Lviv National University of Veterinary Medicine and Biotechnology. S. Z. Gzhytsky, 2018, vol. 20, № 88, pp. 85-88. (in Ukrainian). DOI https://doi.org/10.32718/nvlvet8815

11. Demchyshyn A. V., Perkyj Ju. B., Gorjuk Ju. V., Gorjuk V. V. Development of a liquid acidifier "Akvasan" for growing broiler chickens. Scientific notes UO VGAVM, 2019, vol. 55, №. 1, pp. 118-121. (in Bilorussian).

12. Kononenko V. K., Ibatullin I. I., Patrov V. S. Workshop on Fundamentals of Scientific Research in Animal Husbandry: Teaching. manual for higher agrar shut up III-IV levels of accreditation from special. Zoo Engineering, Kyiv, 2000, p. 96. (in Ukrainian).

Рецензент - Я. Й. Крижанівський, канд. вет. наук, с. н. с., Тернопільська дослідна станція Інституту ветеринарної медицини НААН.

УДК 619:615.5

doi: 10.36359/scivp.2019-20-2.11

\title{
ВПЛИВ СОЛЕЙ ПОЛІГЕКСАМЕТИЛЕНГУАНІДИНУ НА ЗАГАЛЬНИЙ РОЗВИТОК ТА СТАН ЦЕНТРАЛЬНОЇ НЕРВОВОЇ СИСТЕМИ ЩУРІВ
}

\author{
I. М. Кушнір, д-р вет. наук, \\ Г. В. Колодій, канд. вет. наук, \\ В. I. Кушнір, канд. вет. наук, \\ I. С. Семен, канд. с.-г. наук, \\ С. Д. Мурська, канд. вет. наук
}

Державний науково-дослідний контрольний інститут ветеринарних препаратів та кормових добавок вул. Донецька, 11, м. Львів, 79019, Україна

Проведено визначення впливу солей полігексамеленгуанідину на емоиіийну й рухову активність щурів. Дослідження проводили за загальновизнаною методикою у тесті «відкритого поля». Результати експерименту вказують на вплив дослідного засобу на иентральну нервову систему тварин IV дослідної групи покоління $F_{1}$ та $F_{2}$, щзо отримували засіб у концентрачії 1,2 мг/кг маси тіла. В результаті проведених досліджень встановлено зменшення рухової активності у щурів, щзо вказує на розвиток гальмування центральної нервової системи та виникнення емочійної реакиії страху. В результаті проведених досліджень встановлено, щзо застосування солей полігексаметиленгуанідину у II дослідній групі не спричинило зміни емочійної та рухової активності тварин.

При визначенні показників постнатального розвитку щуренят покоління $F_{1}$ та $F_{2}$ було 
встановлено, щзо поява шерстного покриву, час відкриття очей та відлипанням вушної раковини у тварин контрольної та II дослідної групи появлялися одночасно, тоді як у III та IV дослідних групах вони відбувалися пізніше, у порівнянні з тваринами контрольної групи.

Ключові слова: ПОЛІГЕКСАМЕТИЛЕНГУАНІДИН, ЩУРИ, ЦЕНТРАЛЬНА НЕРВОВА СИСТЕМА, ПОВЕДІНКОВІ РЕАКЦІЇ, ВІДКРИТЕ ПОЛЕ, РУХОВА АКТИВНІСТЬ.

До одних із перспективних дезінфікуючих засобів відносяться полімерні біоцидні препарати природного чи синтетичного походження. Серед широкого спектру біоцидних препаратів у ветеринарній практиці виділяються групи полімерних сполук на основі полігексаметиленгуанідин-гідрохлориду та полігексаметиленгуанідин-фосфату. Спектр біоцидної дії полігексаметиленгуанідину (ПГМГ) досить широкий і направлений як проти грампозитивних, так і грамнегативних бактерій, а також плісеневих та дріжджоподібних мікроскопічних грибів $[1,2]$.

Більшість дезінфектантів, що традиційно застосовуються для дезінфекції, є досить дорогими, часто малоефективними щодо патогенних мікроорганізмів або можуть у своєму складі містити компоненти, які $\epsilon$ токсичними, що створює небезпеку для здоров'я макроорганізму, і відповідно за цих умов сприяють погіршенню санітарно-екологічного стану тваринницьких об’ єктів. Власне тому, при обиранні дезінфікуючого засобу слід звертати увагу не лише на його спектр антимікробної дії, а також і на відсутність токсичної дії [3].

Оскільки сьогодні збільшується асортимент дезінфікуючих засобів, тому для виявлення шкідливої дії на організм тварин, виникає гостра необхідність проведення їх всебічної оцінки. 3 огляду на це при розробці нових дезінфікуючих засобів надзвичайно важливим етапом $\epsilon$ проведення токсикологічних досліджень.

За цих умов, важливим $є$ вивчення впливу солей ПГМГ на стан центральної нервової системи нащадків білих щурів покоління $\mathrm{F}_{1}$ та $\mathrm{F}_{2}$. При цьому найпоширенішим та найінформативнішим тестом $\epsilon$ вивчення емоційно-поведінкових реакцій $[4,5]$.

Метою наших досліджень було вивчення впливу солей ПГМГ на загальний розвиток та центральну нервову систему білих щурів.

Матеріал і методи. Досліджуваний засіб представляє собою 25 \% водний безбарвний або з жовтуватим відтінком розчин солей ПГМГ гідрохлориду та фосфату. Експериментальні дослідження проводили на щурах самках лінії Вістар з початковою масою тіла 180-200 г. До початку експерименту тварин утримували в стандартних умовах віварію за природного освітлення та годівлі. Вагітних самок було розподілено на 4 групи, по 5 тварин у кожній. Перша група тварин була контрольною та отримувала звичайну питну воду, II дослідна група -досліджуваний засіб у концентрації 0,12 мг/кг, III - 0,6 мг/кг та IV - 1,2 мг/кг маси тіла. Досліджуваний засіб застосовували, починаючи із першого дня та упродовж всієї вагітності самок. Після народження щуренят, з метою отримання даних щодо загального розвитку щурів, зокрема: появи шерстного покриву, часом відкриття очей та відлипанням вушної раковини, щоденно проводили спостереження за тваринами [6].

Для визначення впливу солей ПГМГ на ріст та розвиток білих щурів покоління $\mathrm{F}_{2}$ iз вагітних самок покоління $\mathrm{F}_{1}$ сформували контрольну та три дослідних групи. Тваринам дослідних груп продовжували застосовувати дослідний засіб у тих самих концентраціях, що і в попередньому експерименті: II - 0,12, III - 0,6, IV - 1,2 мг/кг маси тіла, а тваринам контрольної групи - воду.

Оцінку впливу засобу на характеристики поведінки тварин покоління $\mathrm{F}_{1}$ проводили шляхом порівняння з відповідними результатами контрольної та трьох дослідних груп.

За допомогою тесту «відкрите поле» вивчали вплив при застосуванні солей ПГМГ на рівень тривожності та дослідницької активності піддослідних щурів. В основі методики «відкрите поле» [7] лежить природний потяг тварин, зокрема гризунів, до дослідження 
незнайомої території, в яку вони потрапляють. Поведінка тварин у тесті «відкрите поле» змінюється залежно від рівнів їхньої тривожності та дослідницької активності $[6,8]$.

Всі дослідження проводили за загальноприйнятими методиками, затвердженими у «Свропейській Конвенції про захист хребетних тварин, які використовуються для експериментальних та наукових цілей» (Страсбург, 1986) [4].

Статистичну обробку результатів проводили за t-критерієм Ст'юдента. Для відповідних розрахунків було використано стандартний пакет програм статистичного аналізу Microsoft Excel.

Результати й обговорення. При вивченні впливу солей ПГМГ на загальний розвиток тварин покоління $\mathrm{F}_{1}$, який враховували за терміном появи шерстного покриву, часом відкриття очей та відлипанням вушної раковини, отримали дані, що наведені у таблиці 1.

Таблиия 1

Показники постнатального розвитку щуренят покоління $\mathrm{F}_{1}$ за застосування солей ПГМГ

\begin{tabular}{|c|c|c|c|}
\hline \multirow{2}{*}{ Групи } & \multicolumn{3}{|c|}{ Термін експерименту, доби } \\
\cline { 2 - 4 } & Поява шерстного покриву & Відкривання очей & Відлипання вушної раковини \\
\hline I & 7 & 15 & 5 \\
\hline II & 7 & 15 & 5 \\
\hline III & $7-8$ & 16 & 7 \\
\hline IV & $7-8$ & 17 & 7 \\
\hline
\end{tabular}

У результаті проведених досліджень встановлено, що шерстний покрив у тварин контрольної та дослідних груп появлявся одночасно на 7 добу після народження. Відкривання очей у щурів контрольної та II дослідної групи найшвидше, зокрема на 15 добу, у тварин III на 16, та у тварин IV групи - на 17 добу. Відлипання вушної раковини у тварин III та IV дослідних груп відзначали, відповідно, на 6 та 7 доби.

Для вивчення особливостей вищої нервової діяльності поведінки щурів застосовували тест «відкрите поле», який характеризується такими величинами: кількістю пересічених квадратів (як показник дослідницької активності), кількістю стійок на задніх кінцівках (як показник дослідницької активності), руховою активністю, нірковим рефлексом (що характеризує пізнавальну активність щурів). Також реєстрували неспецифічну поведінку тварин: вегетативну - по кількості актів дефекації, які значною мірою залежать від режиму харчування тварини та фізіологічного стану іiі травної системи. Збільшення числа дефекацій та уринацій може свідчити про вищий рівень тривожності тварини, а також про порушення функціонування шлунково-кишкового тракту та сечовидільної систем. Основним показником, який вказує на відсутність страху та повну адаптацію тварин до незвичних умов навколишнього середовища, $є$ грумінг (вмивання, чистка, почухування за відповідну одиницю часу).

При визначенні впливу солей ПГМГ на функціональний стан центральної нервової системи щурів отримали дані, що наведені у таблиці 2.

Поведінкові реакції білих щурів покоління $\mathrm{F}_{1}$

Табличя 2 за застосування солей ПГМГ $(\mathrm{M} \pm \mathbf{m}, \mathbf{n}=\mathbf{5})$

\begin{tabular}{|l|c|c|c|c|}
\hline \multicolumn{1}{|c|}{ Показники } & \multicolumn{4}{c|}{ Групи тварин } \\
\cline { 2 - 5 } & I & II & III & IV \\
\hline Кількість пересічень квадратів & $13 \pm 0,3$ & $13,2 \pm 0,3$ & $12,8 \pm 0,4$ & $11,4 \pm 0,6^{*}$ \\
\hline Кількість стійок на задніх лапках & $1,8 \pm 0,3$ & $2 \pm 0,4$ & $1,6 \pm 0,2$ & $1,4 \pm 0,2$ \\
\hline Кількість заглядань в нірки & $3,8 \pm 0,3$ & $4 \pm 0,3$ & $3,4 \pm 0,2$ & $3 \pm 0,3$ \\
\hline Кількість умивань (грумінг) & $2,6 \pm 0,4$ & $2,8 \pm 0,4$ & $2,3 \pm 0,4$ & $2 \pm 0,5$ \\
\hline Кількість актів дефекацій & $2,6 \pm 0,4$ & $2,8 \pm 0,3$ & $3,2 \pm 0,4$ & $3,4 \pm 0,3$ \\
\hline Кількість актів уринацій & $1,6 \pm 0,4$ & $1,8 \pm 0,4$ & $1,8 \pm 0,4$ & $2,2 \pm 0,5$ \\
\hline
\end{tabular}

Примітка: ступінь вірогідності до контролю *p<0,05 
Установлено вірогідне зменшення кількості перетинів квадратів на 12,3 \% (p<0,05), у порівнянні до тварин контрольної групи. У тварин III та IV дослідних груп дещо зменшеними були такі показники, як кількість вертикальних стійок на задніх лапках, відповідно, на 11 та 22,2 \%, кількість заглядань в нірки, відповідно, на 11 та $21 \%$, кількість умивань, відповідно, на 21 та 23 \%. За цих умов, кількість актів дефекацій та уринацій у тварин IV дослідної групи була збільшеною, відповідно, на 31 та 37,5 \%.

Визначення показників постнатального розвитку щуренят покоління $\mathrm{F}_{2}$ наведено у таблиці 3.

Показники постнатального розвитку щуренят покоління $\mathrm{F}_{2}(\mathrm{M} \pm \mathrm{m}, \mathrm{n}=5)$

\begin{tabular}{|c|c|c|c|}
\hline \multirow{2}{*}{ Групи } & \multicolumn{3}{|c|}{ Термін експерименту, доба } \\
\cline { 2 - 4 } & Поява шерстного покриву & Відкривання очей & Відлипання вушної раковини \\
\hline I & 7 & 15 & 5 \\
\hline II & 7 & 15 & 5 \\
\hline III & 8 & 16 & 6 \\
\hline IV & 8 & 17 & 7 \\
\hline
\end{tabular}

Як бачимо з даних таблиці 3, шерстний покрив у тварин контрольної та II дослідних груп появлявся одночасно, на 7 добу після народження, тоді як у тварин III та IV дослідних груп - на 8. Відкривання очей у щурів контрольної та II дослідної групи виявляли на 15 добу, у тварин III - на 16 та найпізніше у тварин IV дослідної групи - на 17 добу. Крім того, відлипання вушної раковини у тварин IV дослідної групи відбувалося також найпізніше, зокрема, на 7 добу.

При визначенні впливу солей ПГМГ на функціональний стан центральної нервової системи щурів покоління $\mathrm{F}_{2}$ отримали дані, наведені у таблиці 4.

\section{Поведінкові реакції білих щурів покоління $\mathrm{F}_{2}$} за застосування солей ПГМГ $(\mathrm{M} \pm \mathrm{m}, \mathrm{n}=5)$

\begin{tabular}{|l|c|c|c|c|}
\hline \multirow{2}{*}{\multicolumn{1}{|c|}{ Показники }} & \multicolumn{4}{c|}{ Групи тварин } \\
\cline { 2 - 5 } & I & II & III & IV \\
\hline Кількість пересічень квадратів & $12,6 \pm 0,4$ & $12,8 \pm 0,4$ & $12 \pm 0,4$ & $10,6 \pm 0,5^{*}$ \\
\hline Кількість стійок на задніх лапках & $1,8 \pm 0,6$ & $1,8 \pm 0,5$ & $1,2 \pm 0,4$ & $1 \pm 0,4$ \\
\hline Кількість заглядань в нірки & $4,2 \pm 0,4$ & $4 \pm 0,3$ & $3,4 \pm 0,2$ & $2,4 \pm 0,4 *$ \\
\hline Кількість умивань (грумінг) & $2,8 \pm 0,4$ & $2,6 \pm 0,2$ & $2 \pm 0,4$ & $1,4 \pm 0,2^{*}$ \\
\hline Кількість актів дефекацій & $2,4 \pm 0,5$ & $2,6 \pm 0,2$ & $3 \pm 0,4$ & $3,4 \pm 0,2$ \\
\hline Кількість актів уринацій & $1,6 \pm 0,4$ & $2,2 \pm 0,2$ & $2,8 \pm 0,4$ & $3,6 \pm 0,2^{*}$ \\
\hline
\end{tabular}

Примітка: ступінь вірогідності до контролю * $\mathrm{P}<0,05$

Аналізуючи поведінкові реакції щурів місячного віку покоління $\mathrm{F}_{2}$, встановлено вірогідне зменшення кількості перетинів квадратів у тварин IV дослідної групи на $\quad 16 \%$ $(\mathrm{p}<0,05)$, у порівнянні до тварин контрольної групи. У тварин III та IV дослідних груп дещо зменшеними були такі показники: кількість вертикальних стійок на задніх лапках, відповідно, на 33 та 44 \%, кількість заглядань у нірки, відповідно, на 19 та 43 \%, кількість умивань, відповідно, на 28,5 та 50 \% (p<0,05). За цих умов кількість актів дефекацій у тварин III та IV дослідних груп була збільшеною, відповідно, на 25 та 42 \% та актів уринацій, відповідно, на 75 та $125 \%(\mathrm{p}<0,05)$.

\section{В И С Н О В К И}

1. Вивчаючи вплив солей полігексаметиленгуанідину на емоційну й рухову активність тварин, порівняно з контролем, нами встановлено, що кількість перетинів квадратів, вертикальних стійок на задніх лапках, кількість заглядань у нірки та умивань у тварин II дослідної групи покоління $\mathrm{F}_{1}$ 
та $\mathrm{F}_{2}$ були в межах результатів тварин контрольної групи. У тварин IV дослідної групи покоління $\mathrm{F}_{1}$ та $\mathrm{F}_{2}$ встановили вірогідне зменшення кількості перетинів квадратів. Зменшення рухової активності у щурів вказує на розвиток гальмування центральної нервової системи та виникнення емоційної реакції страху. При цьому кількість актів дефекації та уринації у тварин III та IV дослідних груп була збільшеною, у порівнянні з контрольною та II дослідною групою, що вказує на тривожний стан щурів.

2. При визначенні показників постнатального розвитку щуренят покоління $\mathrm{F}_{1}$ та $\quad \mathrm{F}_{2}$ було встановлено, що поява шерстного покриву, час відкриття очей та відлипанням вушної раковини у тварин контрольної та II дослідних груп появлялися одночасно, тоді як у III та IV дослідних групах — на 1-2 доби пізніше, порівняно з контролем.

Перспективи досліджень. Розробка методів контролю на дезінфікуючий засіб, що виготовлений на основі солей ПГМГ.

\section{THE INFLUENCE OF POLYHEXAMETHYLENE GUANIDINE SALTS ON THE GENERAL DEVELOPMENT AND STATUS OF THE CENTRAL NERVOUS SYSTEM OF RATS}

\section{M. Kushnir, G. V. Kolodiy, V. I. Kushnir, I. S. Semen, S. D. Murska}

State Scientific Research Control Institute of Veterinary Medicinal Products and Feed Additives, 11, Donetska str., Lviv, 79019, Ukraine

\section{S U M M A R Y}

It was conducted the determination of the influence of disinfectant, which is a $25 \%$ aqueous solution of salts of polyhexamethyleneguanidine hydrochloride and polyhexamethylene guanidine phosphate, on the emotional and motor activity of rats. The research was made according to the generally accepted methodology in open field test. The assesment of the influence of the investigated mean on the behavior of white rats of the generations $F_{1}$ and $F_{2}$ was carried out by comparison with the corresponding results of the control and three experimental groups.

The results of the experiment indicate on the influence of the investigated mean on the central nervous system of animals in the experimental group IV, in generations of $F_{1}$ and $F_{2}$, which got a drug in a concentration of $1.2 \mathrm{mg} / \mathrm{kg}$ body weight. It was found out the decrease such indicators as the amount of vertical racks on the hind legs, the amount of looking into the holes and the amount of washings. Herewith the amount of acts of defecation and urination in animals of the IV experimental group was increased, which may indicate into the development of inhibition of the central nervous system and the emergence of an emotional reaction to fear. As a result of the studies, it was found out that the use of the investigated mean, created on the basis of polyhexamethylene guanidine salts, in the second experimental group did not change the emotional and motor activity of animals.

In determining the indicators of postnatal development of $F_{1}$ and $F_{2}$ generation of rats, it was found out that the appearance of fur, eye opening, and peeling off the auricle in control animals and the second experimental group appeared at the same time. Whereas in the 3rd and 4th experimental groups, which got the investigated means in a concentrations, respectively, 0.6 and $1.2 \mathrm{mg} / \mathrm{kg}$ body weight, noted that fur covering happened over 7-8 days after birth, eye opening, respectively, on 16 and 17 days. Furthermore, peeling off the auricle in the animals of the 4th experimental group, it also occurred later, in particular, on the 7 days.

Keywords: POLYHEXAMETHYLENEGUANIDINE, RATS, CENTRAL NERVOUS SYSTEM, BEHAVIOR REACTIONS, OPEN FIELD, MOVEMENT ACTIVITY. 


\title{
ВЛИЯНИЕ СОЛЕЙ ПОЛИГЕКСАМЕТИЛЕНГУАНИДИНА НА ОБЩИЕ РАЗВИТИЕ И СОСТОЯНИЕ ЦЕНТРАЛЬНОЙ НЕРВНОЙ СИСТЕМЫ КРЫС
}

\author{
И. М. Кушнир, Г. В. Колодий, В. И.Кушнир, И. С. Семен, С. Д. Мурская
}
Государственный научно-исследовательский контрольный институт ветеринарных препаратов и кормовых добавок ул. Донецкая, 11, г. Львов, 79019, Украина

\section{А Н Н О Т А ЦИ Я}

Проведено определение влияния солей полигексамеленгуанидина на эмоциональную и двигательную активность крыс. Исследования проводили по общепринятой методике в тестах «открытого поля». Результаты эксперимента указывают на влияние исследовательского средства на центральную нервную систему животных IV опытной группы поколения $\mathrm{F}_{1}$ и $\mathrm{F}_{2}$, которые получали средство в концентрации 1,2 мг/кг массы тела. В результате проведенных исследований установлено уменьшение двигательной активности у крыс, что указывает на развитие торможения центральной нервной системы и возникновение эмоциональной реакции страха.

В результате проведенных исследований установлено, что применение солей полигексаметиленгуанидина во II опытной группе не повлекло изменения эмоциональной и двигательной активности животных.

При определении показателей постнатального развития крысят поколения $\mathrm{F}_{1}$ и $\mathrm{F}_{2}$ было установлено, что появление шерстного покрова, время открытия глаз и отлипание ушной раковины у животных контрольной и II опытной группы появлялись одновременно, тогда как в III и IV опытных группах, они происходили позже, по сравнению с животными контрольной группы.

КлючевЫе слова: ПОЛИГЕКСАМЕТЛЕНГУАНИДИН, КРЫСЫ, ЦЕНТРАЛЬНАЯ НЕРВНАЯ СИСТЕМА, ПОВЕДЕНЧЕСКИЕ РЕАКЦИИ, ОТКРЫТОЕ ПОЛЕ, ДВИГАТЕЛЬНАЯ АКТИВНОСТЬ.

\section{Л I T E P A T Y P A}

1. Zhou Z. Interactions of biocidal guanidine hydrochloride polymer analogs with model membranes: a comparative biophysical study / Z. Zhou, A. Zheng, J. Zhong // Acta Biochimica et Biophysica Sinica. - 2011. - Vol. 43. - № 9. - P. 729-737.

2. Artemova T. Z. The problem in the reactivation of microorganisms on evaluating the efficacy of water disinfectants / T. Z. Artemova, A. E. Nedachin, Z. I. Zholdakova [et al] // Gig. Sanit. -2010. - Vol. 1. - P. 15-18.

3. Якубчак О. М. Ветеринарна дезінфекція. К.: Компанія Біопром. $-2010 .-152$ с.

4. European convention for the protection of vertebrate animals used for experimental and other scientifi c purposes // Council of European. - Strasbourg. - 1986. - №123. - 51 p.

5. Сучасні проблеми біоетики / Відп. ред. Ю.І. Кундієв. - К.: «Академперіодика». - 2009. $278 \mathrm{c}$.

6. Буреш Я. Методики и основные эксперименты по изучению мозга и поведения / Я. Буреш, О. Бурешова, Д. Хьюстон // М.: Высш. Школа. - 1991. - 399 с.

7. Hall C. S. A study of the rat's behavior in a field: a contribution to method in comparative psychology / C. S. Hall, E. L. Ballachey // University of California Publications in Psychology. - 1932. Vol. 6. - P. 1-12. 
8. Калуев A. В. Стресс, тревожность и поведение: актуальные проблемы моделирования тревожного поведения у животных / А. В. Калуев // - К. : CSF. - 1998. - 98 с.

\section{References}

1. Zhou Z. Interactions of biocidal guanidine hydrochloride polymer analogs with model membranes: a comparative biophysical study / Z. Zhou, A. Zheng, J. Zhong // Acta Biochimica et Biophysica Sinica. - 2011. - Vol. 43. - № 9. - P. 729-737.

2. Artemova T. Z. The problem in the reactivation of microorganisms on evaluating the efficacy of water disinfectants / T. Z. Artemova, A. E. Nedachin, Z. I. Zholdakova [et al] // Gig. Sanit. -2010. - Vol. 1. - P. 15-18. Ukrainian).

3. Yakubchak O. M. Veterinarna dezinfekcia. K.: Kompania Bioprom . - 2010. - 152 s. (in

4. European convention for the protection of vertebrate animals used for experimental and other scientifi c purposes // Council of European. - Strasbourg. - 1986. - №123. - 51 p.

5. Suchasni problemy bioetyky / Vidp. red. Y. I. Kundiev. - K.: «Academiperiodyca». - 2009. 278 s. (in Ukrainian).

6. Buresh Y. Methodiky i osnovnye experimenty po izycheniy mozga y povedenia / Y. Buresh, O. Bureshova, D. Houston // M .: Visch. shcola. - 1991 - 399 s. (in Russian).

7. Hall C. S. A study of the rat's behavior in a field: a contribution to method in comparative psychology / C. S. Hall, E. L. Ballachey // University of California Publications in Psychology. - 1932.Vol. 6. - P. 1-12.

8. Kaluev A. V. Stress, trevognost i povedenie: actyalnye problemy modelirovania trevognogo povedenya u gyvotnykh / A. V. Kaluev // - K. : CSF. - 1998. - 98 s. (in Russian).

Рецензент - Т. Р. Левицький, к. с.-г. н., ДНДКІ ветпрепаратів та кормових добавок. 